This item was submitted to Loughborough's Research Repository by the author.

Items in Figshare are protected by copyright, with all rights reserved, unless otherwise indicated.

\title{
Investigating the underlying social psychology of the innovation adoption in container trucking industry
}

PLEASE CITE THE PUBLISHED VERSION

https://doi.org/10.1016/j.tra.2020.05.016

PUBLISHER

Elsevier

VERSION

AM (Accepted Manuscript)

\section{PUBLISHER STATEMENT}

This paper was accepted for publication in the journal Transportation Research Part A: Policy and Practice and the definitive published version is available at https://doi.org/10.1016/j.tra.2020.05.016.

\section{LICENCE}

CC BY-NC-ND 4.0

\section{REPOSITORY RECORD}

Chen, Yang, Kan Tao, Wendy Jiao, and Dong Yang. 2020. "Investigating the Underlying Social Psychology of the Innovation Adoption in Container Trucking Industry”. Loughborough University. 


\section{Investigating the underlying social psychology of the innovation adoption in container trucking industry}

Abstract: Most extant literature in the transportation industry views innovation adoption as a rational choice process conducted on a cost-benefit calculation basis. This restricts our understanding of innovation decisions made by individuals embedded in a social-economic context. By investigating the underlying social psychology of the innovation adoption in the Chinese container trucking industry, this paper aims to answer the question as to "why trucking operators postpone adopting the cargo-truck matching system during its early stage'. In order to achieve the research objective, a mixed methods research framework is proposed. First, we conduct four in-depth interviews using semi-structured questionnaires to investigate the contextualized behavior of individuals, based on which three hypotheses are developed. Second, based on the data collected from an online questionnaire survey covering 282 trucking operators in Ningbo, the proposed empirical hypotheses are tested using a discrete choice model. We find that risk tolerance positively moderates influence of the status quo on the innovation adoption decision, whilst the effect on it of service-orientation is negative.

Keywords: Innovation adoption, Social psychology, Container trucking industry, Mixed methods, Platformization

\section{Introduction}

Technological and managerial innovations are rapidly changing the traditional way of organization and production in the transportation industry. Chen et al. (2019) report on an innovative internet-based mode of industry organization in China that is significantly improving efficiency of the traditional freight forwarding industry. Although extant transportation literature has already identified innovation adoptions as being positively associated with an expectation of performance improvements, most of them are conducted on a cost-benefit calculation basis. For example, Subramanian et al. (2015) find that perceived reduction in cost triggered the adoption of integrated service and cloud computing among small and medium logistics 
33 providers; Similarly, Wang et al., (2018) support the idea that perceived usefulness

34 has a positive effect on adoption intention, the effect on it of perceived risks is 35 negative. Nguyen (2013) suggests that the principal components influencing 36 e-business adoption decisions includes the large initial investment expense, financial constraints, and costs of operation etc; Oláh et al. (2018) study logistics service providers in Hungary, and reveal the fact that sector-specific information technology development is positively accompanied by a significant improvement in outcomes. It is noticed that the literature generally focuses on economic factors, but usually overlooks the underlying social psychology of innovation adoption, particularly in the early stages, which is of great importance to innovation diffusion in terms of accumulating enough seed users to trigger a bandwagon effect for the later stages. (Abrahamson and Rosenkopf, 1993). Orlikowski and Barley (2001) suggest that "Socio-technical systems theorists, for instance, who initially studied technologies as concrete objects and championed the idea that technical and social systems are reciprocally constitutive, ... framed technology as a process that required inputs and produced outputs with degrees of variation". This indicates that innovation adoption should be considered as a back and forth process along with resistances and compromises, rather than assuming it to be a simple one-way process. As Orlikowski and Barley (2001) explain, most extant literature treats technology "as a material cause, of abstracting away from the specifics of a design, and of ignoring the role of a human agency". Abrahamson and Rosenkopf (1993) point out that, during the early stage of a two-stage model of innovation diffusion, when a high level of ambiguity renders unclear about "what returns", "the range of returns it may produce and the probability of these outcomes" and "whether returns expected from an innovation will be appropriate in future environments", the social process is even more important in achieving that critical number of seed users that will trigger the bandwagon effect for the second stage.

It is noticed that the analysis of underlying social psychology of innovation adoption in transportation research is still in its infancy. Therefore, this study focuses on the underlying social psychology of internet-based platformization in the Chinese container trucking industry, exploring the reason 'why trucking operators postpone adopting innovation during the early stage'. This study builds upon the previous literature by providing an alternative explanation complementary to the materialism-based view of innovation adoption in transportation literature. It will also 
enlighten practitioners, including both managers in the trucking industry and government agencies, so as to help them formulate better initiating strategies that will attract more usage, thus achieving the critical number of infusion seed users that will facilitate better diffusion in the later stages.

\section{Literature review}

Technological progress and management innovation are the prime factors driving efficiency improvement in the transportation industry. Therefore, innovation adoption has attracted much interest from academia. The question that has been widely addressed in the extant literature is about the factors leading to the adoption of innovation. Research has proved, in fact, that the adoption of new technology can be attributed to economic reasons (Oláh et al., 2018, Chen et al., 2019, Wolf and Seebauer, 2014, Petschnig et al., 2014). For example, Liu et al. (2019) show that individuals with a higher income and who perceive higher benefits are more likely to pay for self-driving vehicles. Similarly, Wolf and Seebauer (2014) suggest that e-bike use is most driven by perceived usefulness, which in turn depends on an easy use, appropriate infrastructure. Chen et al. (2019) suggest that the adoption of autonomous vehicles should be promoted by subsidizing their purchase, with the objective of system optimization subject to a fixed budget. Zeng et al. (2018) comprehensively examine factors affecting the economic impact of logistics vehicles using electronic variable transmission hybrid power systems, estimating the cost and cost recovery cycle under different conditions. Their research affirms the economic advantages of the new practice. One recent study on electric van adoption shows that concerns related to range, queue, payload and electricity grid are reducing its acceptance among last mile operators in London and Paris (Morganti and Browne, 2018); management innovation adoption also reflects similar characteristics, as is the case too with new technology deployment. For example, the literature has also identified various factors that inhibit e-business adoption in supply chain management (Oliveira and Martins, 2010; Matopoulos et al., 2007). In a mixed methods case study, Gunasekaran and Ngai (2008) develop a conceptual framework for the adoption of e-procurement based on a questionnaire survey, identifying four constructs influencing the implementation of e-procurement, including perceived benefits of e-procurement, perceived barriers to e-procurement, critical success factors of 
e-procurement adoption, and perceived organizational performance with

101 e-procurement. Nguyen (2013) finds that e-business adoption benefits service quality

102 in terms of a higher level of competitiveness, service differentiation, and value adding,

103 as well as improved customer service and supply chain integration. At the same time,

104 though, Nguyen also highlights factors that inhibit the new practice, including the

105 high initial investment expense, financial constraints, and costs of operation etc.

106 Several studies also focus on the safety technology adoption in trucking industry. For

107 example, Cantor, Corsi and Grimm (2006) find the larger firms, with a broad

108 geographic scope of operations, are the leaders of the adoption. But few of them

109 investigate into the mechanism by which innovation is adopted.

110 From the perspective of organizational sociology, the status quo of innovation

111 adoption can be best described as materialism-oriented research, which, as Orlikowski

112 and Barley (2001) suggested, refers to "conceptualized technology abstractly",

113 "treated it deterministically (often as a material cause)" and "ignored the role of a

114 human agency in shaping either the design or the use of the technology". In other

115 words, the economic analysis in existing literature is based on a cost-benefit

116 calculation. It detaches the innovation from its embedded context by ignoring the

117 social factors involved, such as the interaction between technology and various

118 adopters, user preferences, and political issues etc. In the remaining part of this

119 section, we would like to briefly review two of the most popular innovation diffusion

120 theories in sociology, these being the two-stage model (Rogers, 2003; Abrahamson

121 and Rosenkopf, 1993) and the innovation resistance theory (Joachim et al., 2018;

122 Talke and Heidenreich, 2013; Ram and Sheth, 1989). Both of these highlight the

123 underlying social and psychological factors in innovation adoption. This literature

124 helps to facilitate our theoretical development in section four.

125 Based on complete-information assumption, proponents of the two-stage model

126 for innovation diffusion propose that little information about the consequence of

127 innovation is disclosed during the early stage. Therefore, the potential adopters are

128 cautious in innovation adoption, which results in a low speed of diffusion at the

129 population level. As the number of adopters increases, more information about the

130 innovation is released, which reduces the uncertainty and ambiguity of a new practice.

131 Once a critical number of seed users is reached, the innovation becomes "infused with

132 value beyond the technical requirements of the task at hand" as Selznick (1957)

133 suggested. And the non-adopters tend to use the innovation to avoid illegitimacy and 
134 get support from their stakeholders (Meyer and Rowan, 1977), this being commonly

135 referred to as institutional pressure or the bandwagon effect (Abrahamson and 136 Rosenkopf, 1993).

137 The two-stage pattern highlights the importance of the critical number (also 138 known as the threshold number) in innovation diffusion. It also has a limitation in 139 reasoning why the early adopters decide to use the innovation. One possible 140 explanation is that early adopters make their decision on a rational basis due to having 141 a greater amount of private information, as well as due to their own characteristics 142 (Rogers, 2003). However, innovation resistance theory challenges the rational 143 decision view by pinpointing the existence of anti-change bias, which results from a 144 generic predisposition of adopters to resist innovations prior to innovation evaluation 145 (Talke and Heidenreich, 2013). This notion stems from Sheth (1981), who indicates 146 that "the typical human tendency is to strive for consistency and status quo rather than 147 to continuously search for, and embrace, new behaviors." Building upon previous 148 literature on passive or active innovation resistance (Ram and Sheth, 1989; 149 Laukkanen et al., 2008; Kleijnen et al., 2009), Talke and Heidenreich (2013) propose 150 an integrated framework to theorize 'how to overcome anti-change bias' at the very 151 beginning of the innovation diffusion. In considering whether Internet platform 152 adoption in the Chinese container trucking industry is beginning to take off, Talke and 153 Heidenreich's theory is quite suitable for investigating our research question.

154 The rest of this paper will be organized as follows: Background information will 155 be provided in section three; in section four, we will introduce our mixed method 156 research design and how we address our research questions combining qualitative and 157 quantitative methods based on data collected from a questionnaire survey; section five 158 presents theoretical hypotheses developed based on the innovation diffusion theories, 159 and associated with four contextualized interviews; empirical analysis results will be 160 displayed in section six, followed by the conclusion and implications in section seven.

\section{3. Case Background: The Last Mile Revolution}

163 Although a trucking service is considered to be the most appropriate method of 164 accomplishing last mile delivery among various transport solutions, the Chinese 165 container trucking industry features high fragmentation and a low level of regulation, 166 which results in extreme inefficiency in its operation. For instance, due to information 167 asymmetry, the no-load rate for Chinese road transport is up to $40 \%$ while that for 
169 a particularly common occurrence near container yards, which, in turn, results in

170 loitering trucks and also places additional burden on the roads. At the macro level, it 171 also contributes to the high cost of logistics in China nationwide that in 2016, for 172 example, accounted for $14.6 \%$ of $\mathrm{GDP}^{1}$. Chinese central governance exhibited its 173 ambition to restructure the trucking industry by issuing a policy to encourage 174 Internet-based platformization in September 2016. The intended goal of the policy 175 can be summarized as follows (also see figure 1), aiming to reshape the market 176 structure to reduce the asymmetry of business information and improve market 177 efficiency accordingly.

178

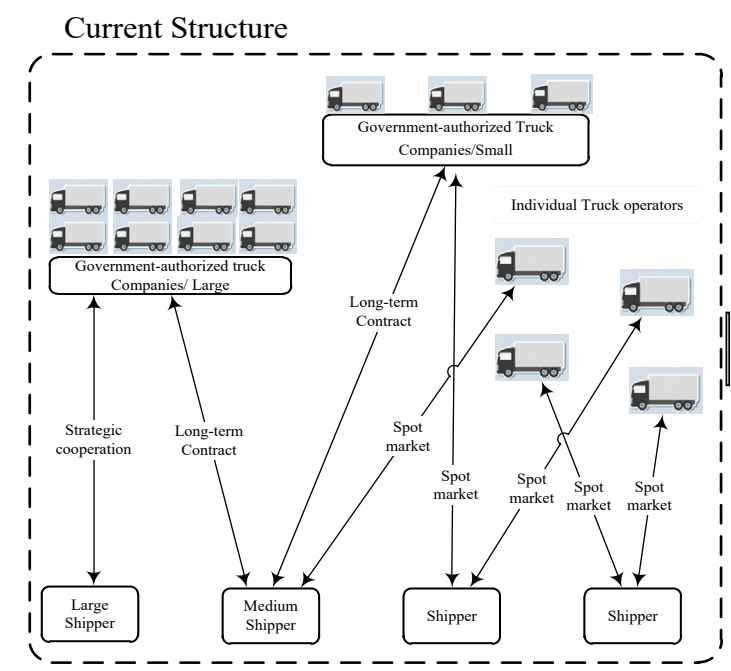

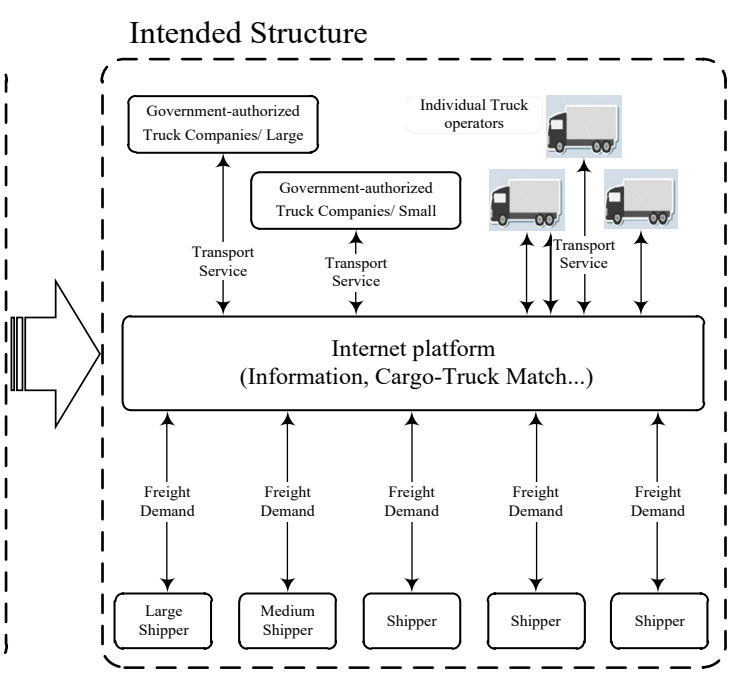

179 180

181

182

183

184

185

186

187

188

189

190

Figure 1. Current and intended structure of Chinese trucking industry (2016)

Currently, there are three main types of representative trucking operators in the market, including 1) large government-authorized truck companies, operating up to hundreds of vehicles; 2) small and medium size government-authorized companies operating a fleet of dozens of trucks; and 3) individual operators with less than 10 trucks (and even single-truck operators). In the container trucking niche market case, the large players are usually state-owned trucking companies affiliated to port groups. For example, Shanghai Logistics Company, which is affiliated to Shanghai International Port Group, operates more than 600 trucks, including 400 standard container trucks, and 100 dangerous cargo container trucks. These operators only serve certain companies, and rarely undertake freight tasks in the spot market,

\footnotetext{
1 Source: National Development and Reform Commission's website, https://www.ndrc.gov.cn/xwdt/ztzl/jdstjjqycb/gzjz/201609/t20160901_1028613.html (access on Dec 5th 2019)
} 
191 whereas small and medium size trucking companies are usually grassroots private 192 enterprises, surviving amid fierce market competition. Although some of these 193 companies have long-term contracts with several cargo-owners, mostly they receive 194 commissions on the spot market to maximize the use of their trucks. Typical 195 individual truck operators are those trucks operated independently under a registered 196 company. The main purpose of this form of organization is to meet the market access 197 requirements of the government, but due to lack of proper training and supervision the 198 service quality of these companies is generally below average. Therefore, they can 199 rarely get long-term contracts and operate on a spot market basis.

200 Inspired by the success of the sharing economy, such as with Uber and Airbnb, 201 the development of information technology, such as internet, geographic information 202 system etc., provides the current trucking market in China with a practicable solution 203 to improve its efficiency which currently stuck with the asymmetry of market 204 information. Therefore, the central government now encourages 'the last mile 205 revolution' by advocating reconstruction of the market using the Internet platform, 206 which is considered as excelling in information that can provide cargo-truck matching. 207 Nowadays, however, this revolution is still in progress, and trucking operators are still 208 feeling for the stones to cross the river, looking for the most suitable model to use in a 209 Chinese context. In the consideration above, our study focuses on the underlying 210 social psychology of the adoption of cargo-truck matching system, addressing 211 research question as 'why trucking operators postpone adopting the cargo-truck 212 matching system during its early stage?'

\section{4. Research Design and Data Collection}

215 Based on Johnson and Onwuegbuzie (2004) and Creswell (2009), we build a 216 mixed-method research framework aiming to achieve a complete and comprehensive 217 understanding of our research question. Pure qualitative research is seen as deficient 218 for our research objective because of the potential for biased interpretations made by 219 the researcher, and for the difficulty in generalizing findings to a large group, while 220 quantitative research is also considered thin in understanding the context or setting in 221 which people behave. On the other hand, by combining both, our research can endow 222 the results with strengths that offset the weaknesses of each. Specifically, we develop 223 our research hypotheses with qualitative data collected from four in-depth interviews 
224 held in the first stage during May 2017 to December 2017; and we then empirically

225 test our hypotheses with quantitative data collected from self-administrated 226 questionnaires (see appendix) in the second stage from January 2018 to June of 2018.

227 In the first stage, we conducted four semi-structured interviews with managers 228 from trucking companies, and a trucking Internet platform respectively (also see table

229 1). Interview questions included, but were not limited to: 1) Introduce your company 230 and business model; 2) Have you ever considered adopting an Internet platform-based 231 business model? Why? (The trucking internet platform was excluded from this 232 question); 3) What is the main advantage/disadvantage of an Internet platform-based 233 business model in your opinion? Table 1 List of Interviewees

\begin{tabular}{ccc}
\hline Interviewee & Position & Affiliation \\
\hline A & Operational Manager & Middle-sized trucking company X \\
B & Operational Manager & Middle-sized trucking company Y \\
C & CEO & Trucking Internet platform Z \\
D & Operational Manager & Trucking Internet platform Z \\
\hline
\end{tabular}

The main purpose of the interviews was to identify the social-psychological 237 factors influencing adoption of the innovation, which has rarely been discussed in 238 extant transportation literature. Based on the findings from the interviews, we then 239 proposed three hypotheses as responses to our research questions.

240 The second stage validates the hypotheses we proposed in the first stage. To 241 complete this, we further conducted a survey using online questionnaires. We 242 collected 178 valid questionnaires out of 282 questionnaires distributed to individual 243 trucking operators in Ningbo who are decision makers on using the platform. 244 Compared to the large government-authorized trucking companies, they have higher 245 tendency to use the platform in the early stage. Among all the questionnaires, 104 246 questionnaires were teased out of our empirical database due to their missing data and 247 to data invalidity resulting from completing the questionnaires in an exceptionally 248 short period (30 seconds), we finally have an effective return ratio of $63.1 \%$. With the 249 valid questionnaires, a logistic regression model was applied to validate the 250 hypotheses we proposed. Figure 2 shows the mixed method research framework we 251 designed to achieve our research objective. 


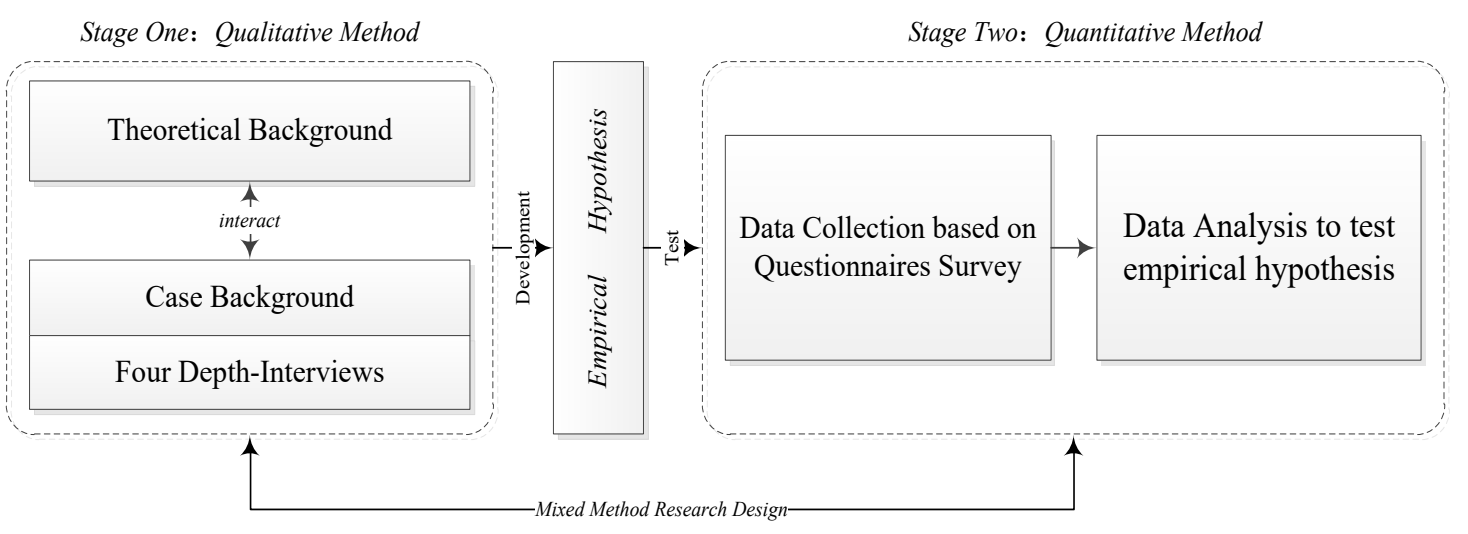

Figure 2. Mixed Method Research Design

\section{Theoretical development and empirical hypotheses}

\subsection{Theoretical development}

257 Individuals find it hard to recognize the existence of an alternative way of practice,

258 especially for those who are satisfied with their status quo (Maguire and Lawrence,

259 2004). One possible explanation for this phenomenon is that socially embedded

260 individuals are also shaped by their institutional context into what is an appropriate

261 way of behavior, including social norms, values and usage pattern (Bagozzi and Lee,

262 1999; Ram and Sheth, 1989). Defaults have significant influence on individuals'

263 decision (Park et al., 2000; Metcalfe \& Dolan 2012). For example, Cantor, Corsi and

264 Grimm (2008) find firms' priority for safety has significant influence on its decision

265 on the adoption of safety technologies. These taken-for-granted approaches further

266 blind them to recognizing alternatives. Talke and Heidenreich (2013) suggest "Such

267 attachment often is irrational so that even alternatives with objectively superior

268 qualities do not get considered". This phenomenon is also known as status quo bias

269 (or anti-change bias) among innovation resistance theorists (Szmigin and Foxall, 1998;

270 Gourville, 2006), and this further prevents innovation from stepping into the

271 evaluation stage.

272 The evaluation stage can also be considered as a social-psychological process,

273 one that does not unfold based purely on cost-benefit calculation and greatly

274 influenced by what our attention is drawn to (Kahneman \& Thaler, 2006). The

275 innovation resistance theory is particularly applicable to the early stage of innovation

276 diffusion when little information is disclosed due to limited scale of adoption at this

277 point. According to the innovation decision model (Talke and Heidenreich, 2013; 
278 Kleijnen et al., 2009; Ram and Sheth, 1989; Roger, 1976), potential adopters still 279 have to overcome their functional and psychological barriers before making the 280 innovation adoption decision. Functional barriers result from consumers perceiving 281 that product attributes are dysfunctional or inadequate for personal needs and usage 282 expectations (Bagozzi and Lee, 1999; Nabih et al., 1997, Talke and Heidenreich, 283 2013), including trialability barriers, complexity barriers, compatibility barriers, and 284 co-dependence barriers, etc. Psychological barriers result from apparent conflict 285 between innovation and consumers' social norms, values, or usage patterns, or if its 286 usage is perceived as being too risky (Kleijnen et al., 2009; Ram and Sheth, 1989), 287 including norm barrier, image barrier, usage barrier, economic risk barrier and social 288 risk barrier etc. Based on the discussion above, we propose a two-stage innovation 289 decision model for early adopters, as shown in Figure 3, this being the theoretical 290 foundation for our contextualized empirical hypotheses in the rest of this section.

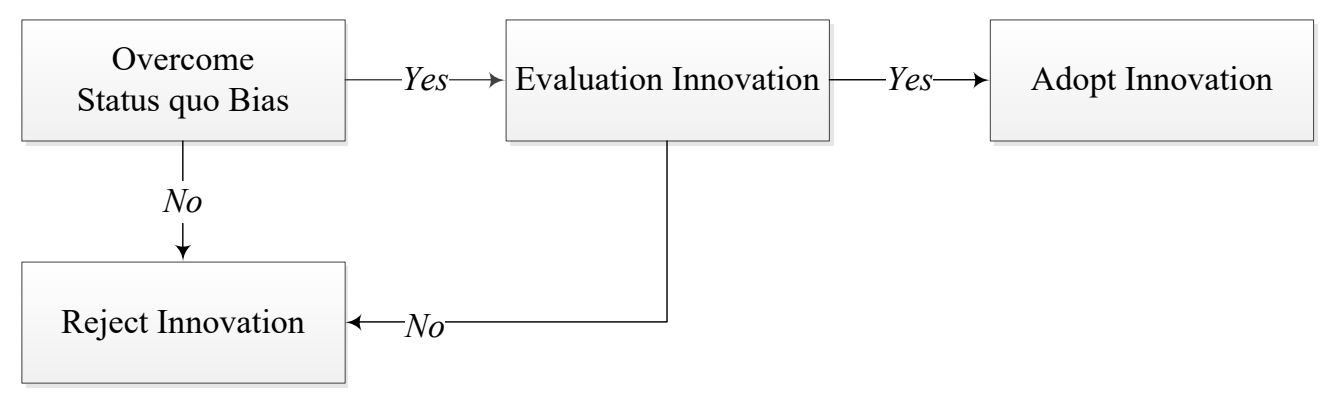

Figure 3. Two-stage innovation decision model for early adopters

\subsection{Empirical hypotheses}

Trucking service is thought of as an under-paid industry with a low threshold for employment, particularly in those more developed provinces lying on the eastern coast of the country. It is noticed that most of the individual trucking operators in this industry are immigrants from the central and western provinces. Therefore, except for the formal organization shown in Figure 1, the trucking industry is also organized on an informal basis, as the migrant practitioners are used to frequently interacting based on their originating provinces, so that practitioners from the same province are more likely to interact with each other not only in business operation but also in their daily life. These informal connections shape practitioners' preferences, values and cognitive characteristics significantly. These informal connections shape practitioners' preferences, values and cognitive characteristics significantly, which plays as a 
reference point when they evaluate the innovation adoption's outcomes (Kahneman and Tversky, 1979). Especially, when the individual trucking operators mentally construe objects that are psychologically near to their reference point appears to be more detailed and contextualized features. When they mentally construe objects distal

311 to their reference point, the construed objects are more like to be abstract and general 312 (Trope, Liberman \& Wakslak, 2007). This thus will influence their thoughts and

313 behaviors. Reflecting on our case, in the city of Ningbo, where we conducted our case 314 study, a large proportion of truck operators are originally from Anhui Province, which 315 is located in the middle of China. If a local trucking company is owned and operated 316 by people from Anhui, most of their employees will also come from the same 317 province. Such trucking operators tend to share business information and cargo offers 318 within their social group, which provides them with more business opportunities, 319 creating a unique reference point compared with trucking operators coming from 320 province other than Anhui. As suggested in the extant status quo literature (Szmigin 321 and Foxall, 1998), such trucking operators are especially biased against the Internet 322 platform-based business, because they are more satisfied with the status quo than are 323 operators coming from other provinces which leads to an increase in the likelihood of 324 them rejecting innovation. Therefore, we propose the first empirical hypothesis for 325 our research question as follows:

H1: Trucking operators (from Anhui) who are more satisfied with their status 329 quo are more likely to reject Internet platform-based business innovation. innovation according to their own criteria, and this too is socially constructed. In our case, at the early stage of innovation diffusion, the trucking industry is also characterized by a higher level of ambiguity associated with usage risk and functional risk. This enhance individual's tendency to overweight potential losses than potential gains (Kahneman and Tversky,1979). To practitioners in the trucking industry, learning from the success of the sharing economy in other sectors, such as Uber and Airbnb, means promoting greater efficiency in industrial operations by integrating decentralized information into an Internet platform endowed with sophisticated technology. However, the other side of the story is that this innovation has to reshape the information flow embedded in an already established business 
341 pattern, which is considered will have potential negative effects on customers' 342 experience. This is consistent with the notion of usage risk proposed in existing 343 literature (Hoeffler, 2003; Ram and Sheth, 1989) referring to "the innovation's 344 inconsistencies with past experiences that threaten to disrupt established usage 345 patterns" as Talke and Heidenreich (2013) suggested. Similarly, some comments in 346 our interview manuscripts echo the usage risk proposition as follows:

347 [1]...The government-authorized trucking companies are less likely to share their exclusive 348 information with others, including the Internet platform, in being afraid of losing their competitive advantage as well as reducing customers' experience... (Comment by an individual trucking operator)

[2]...We identify ourselves as an information provider in order to avoid potential conflict of interests with trucking companies. This strategy also facilitates our cooperation with these companies in the future... (Comment by an Internet platform operator)

353 Furthermore, functional risks also can be identified. Functional risk refers to the 354 function reliability and performance uncertainty (Ram and Sheth, 1989) during the 355 early stage of innovation diffusion. For example, more than 20 technicians are 356 employed in an anonymous Internet platform-based trucking company, and their main 357 responsibilities are to improve the function and usage experience of the Internet 358 platform based on customer feedback. At the time we conducted our interview in 359 November 2017, this company had already released three major software upgrades 360 that significantly enhanced their customers' experience. Although all the apparent 361 risks may postpone trucking operators' decisions on innovation adoption, their 362 influence may still vary among individuals. It is thus likely that individuals with a 363 higher risk tolerance will adopt the innovation, whereas others will postpone their 364 decision, waiting for additional information disclosure to reduce their caution. 365 Therefore, we propose our second empirical hypothesis as follows:

H2: Trucking operator risk tolerance positively moderates the effect of their status quo bias on their innovation adoption decision.

Extant research also indicates that individuals tend to evaluate the investment required as well as the transitional cost resulting from adopting a new pattern compared to the old one (Nguyen, 2013; Woodside and Biemans 2005). For example,

373 after a behavioral experiment, Noussai et al. (2004) highlight the fact that price is 
374 always the foremost consideration for consumers when they are choosing a new 375 product. Dhebar (1996) suggests it is not the price, but concern about how well spent 376 this investment really is on a long-term basis, that makes consumers postpone their 377 decision about whether to adopt innovation or not. These findings are in line with the 378 notion of economic risk barriers in innovation adoption, which refers to "perceiving 379 that innovation's costs are too high and the investment would be a waste of financial 380 resources" as Joachim, Spieth and Heidenreich, (2018) suggested. Reflecting on our 381 case, we notice the fact that service-oriented trucking operators are the ones most 382 welcomed by shippers in the current market and are offered a large number of orders. 383 The following comment was also made by a manager in a small trucking company:

[3]...Well-trained and service-oriented trucking operators are the most valuable resources in the trucking market. Our customers are usually large manufacturers and international traders. They pay great attention to the quality and attitude of our service, and once we fail in meeting up to their requirements this will have serious consequences...

Therefore, trucking operators with service-orientation are less likely to shift to a new pattern, considering that they will have to pay a higher transitional cost than their counterparts with less service-orientation and insufficient orders in the current market. From the discussion above, we finally reach our third empirical hypothesis as follows:

H3: Trucking operator service-orientation negatively moderates the effect of their status quo bias on the innovation adoption decision.

In summary, we propose our empirical framework applied for trucking industry in China in Figure 4.

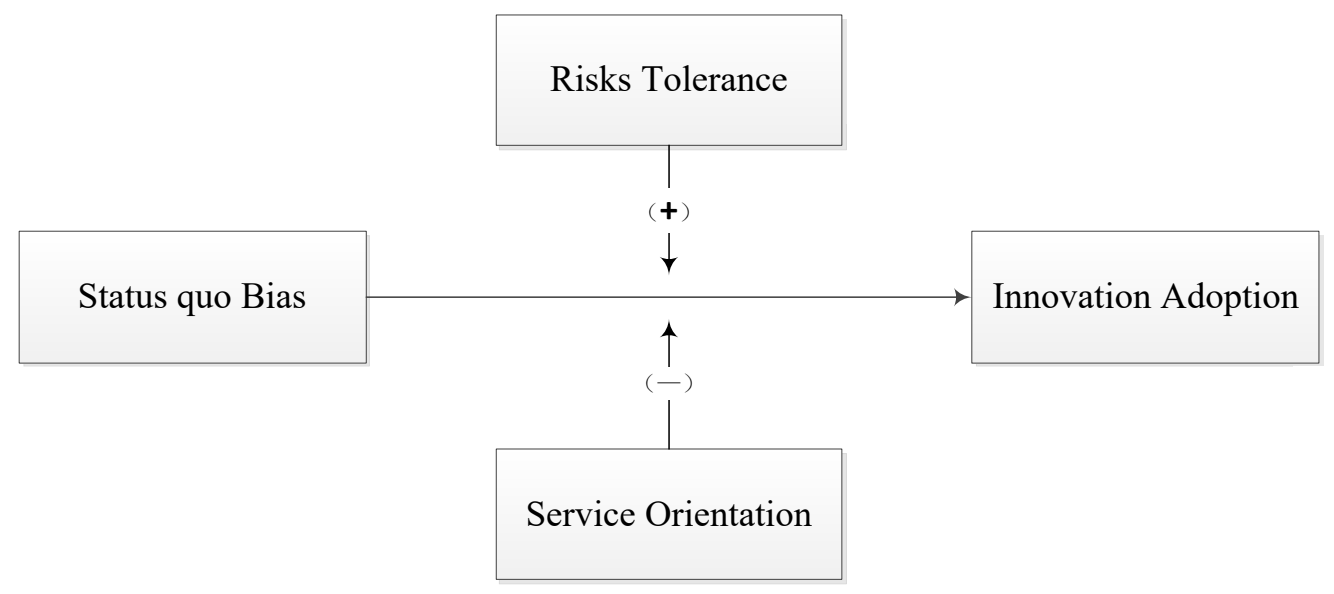




\section{Data Analysis and Results}

\subsection{Model description}

Using the survey data we collected, this section quantitatively tests our hypotheses in a logistic regression model. In the model, we denote $P$ as the probability of $I A$ (Innovation Adoption) $=1$ condition on our independent variables. Our logistic regression model is illustrated as follows:

$$
\log \left(\frac{P}{1-P}\right)=\beta_{0}+\beta_{1} S Q B+\beta_{2} R T+\beta_{3} S O+\beta_{4} S Q B \times R T+\beta_{5} S Q B \times S O+\beta_{6} \text { Gender }
$$

$$
+\beta_{7} A g e+\beta_{8} E B+\beta_{9} D E+\beta_{10} F S+\varepsilon
$$

Where $S Q B$ indicates the Status Quo Basis, $R T$ means Risks Tolerance, $S O$ is Service Orientation, Gender and Age denotes the gender and age of the trucking company operator respectively, $E B$ is Educational Background, $D E$ is Driving Experience and $F S$ is Firm Size.

$S Q B$ is defined by whether the trucking company operator comes from Anhui, and is used to test hypothesis $1(\boldsymbol{H} 1)$. We value the variable with 1 if the respondent comes from Anhui province, 0 otherwise; two moderate variables, including $R T$ and $S O$, are measured in a "behavioral experiment" approach. The respondents are provided with the scenario test as follows:

Scenario I: When you are on your way to $C$ to deliver a consignment, another customer offers you a shipment from $D$ (as the "threaten to disrupt established usage patterns"). If you accept this shipment, you have to make a detour to receive the goods from $D$, which may result in the chance of a one-hour delay in the delivery to $C$. Will you accept the additional shipment?

A. I won't, because there is a chance of a one-hour delay in my delivery to C;

B. If the chance of a one-hour delay in the delivery to $\mathrm{C}$ is less than $\mathbf{1 5 \%}$, I will;

C. If the chance of a one-hour delay in the delivery to $\mathrm{C}$ is less than $\mathbf{3 0 \%}$, I will.

To avoid mutual interference among given options, in Scenario I we first ask the respondents to choose one option from $\mathbf{A}$ and $\mathbf{C}$. In case they choose $\mathbf{A}$, we further provide option $\mathbf{B}$ and ask them to choose one from $\mathbf{A}$ and $\mathbf{B}$. We also adopt a similar questioning strategy for Scenario II.

Risk tolerance $(R T)$ is defined as a discrete variable, measured by the context-specific test in Scenario $I$. We value the construct with 3 if the respondent 
431 chooses A, 2 if the respondent chooses B, 1 if the respondent chooses $\mathrm{C}$. This variable 432 is used to test Hypothesis $2(\boldsymbol{H} 2)$.

433 Scenario II: You are assigned to collect cargo at place Beilun at 10 o' clock 434 tomorrow morning (Monday). If you are living in place Cixi, which is located 65 435 kilometers from Beilun, when do you plan to drive to Beilun to receive the cargo 436 (meet up "the high requirement from customers") (Note: Regardless of traffic 437 congestion, it usually takes about an hour to drive from Cixi to Beilun.)

A. Later than 09:00

B. $08: 30$ to $09: 00$

C. 08:00 to $08: 30$

D. 07:30 to $08: 00$

E. Earlier than 07:30

Service Orientation $(S O)$ is also a discrete variable, measured by the context-specific test in Scenario II:

In Ningbo, it is quite common for container-trucking operators to pick-up containers in Beilun, where container yard is located, before they drive to the designated location for a delivery. Cixi is a county located 65 kilometers away from Beilun (also see figure 5). It usually takes about an hour to drive from Beilun to Cixi. There is always a traffic congestion on Monday morning due to few deliveries in the weekend. It thus normally takes more than one hour for the container-trucking operators to drive from Beilun to Cixi on Monday morning. As a result, if the container-trucking driver leave exactly one hour ahead of the delivery time, they are likely to be late. They know this fact very well, alternatively, some of them leave earlier to increase the chance of reaching their customers in time. With this in mind, we assume that the more additional time a container-trucking operator willing to sacrifice in order to ensure an on-time delivery, the more service-orientation the operator is. Based on this understanding, we design the Scenario II."

We value the construct with 1 if the respondent chooses $A, 2$ if the respondent chooses B, 3 if the respondent chooses C, 4 if the respondent chooses D and 5 if the respondent chooses E. This is used to test hypothesis $3(\boldsymbol{H 3})$.

We also control gender, age, education background $(E B)$, driving experience $(D E)$

462 and firm size $(F S)$ in this model. Operating characteristics, including type of service, 463 type of goods and etc., as suggested by Golob \& Regan (2002) incorporated into our 464 model due to the fact that our empirical setting limited to container trucking service, 

warehouse/factory to container terminal. Therefore, we have excluded these counterfactuals resulted from operating characteristics among our respondents. The detailed description of variables in the model is presented in Table 2.

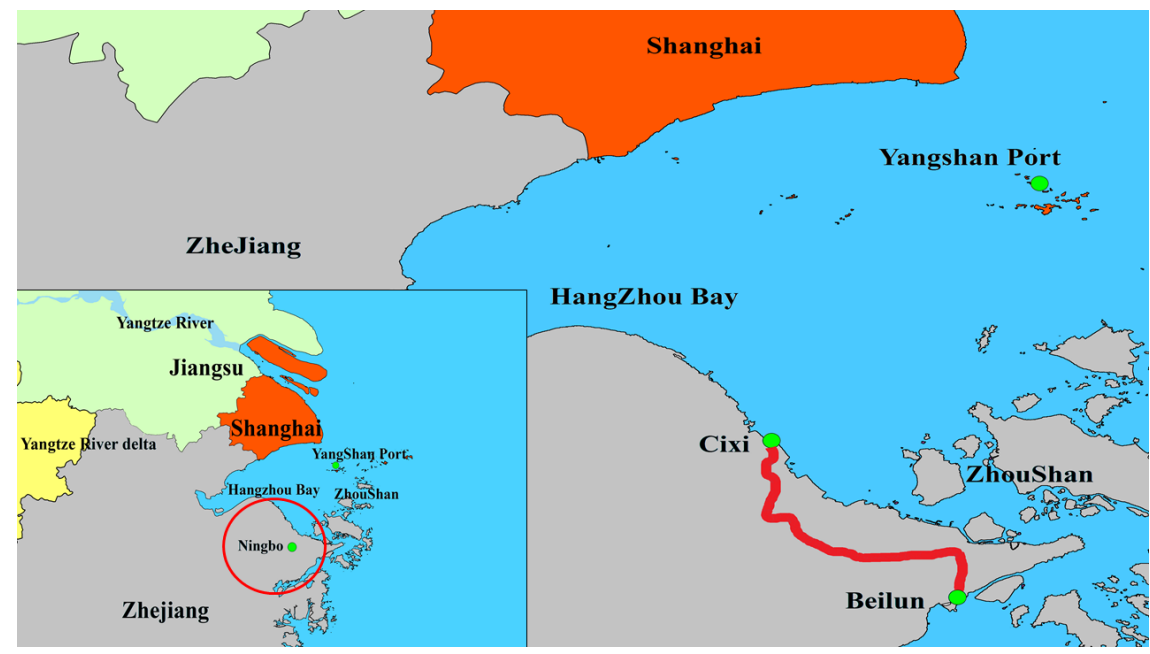

Figure 5 The geographic locations of Scenario II

Table 2. Description of Variables

\begin{tabular}{|c|c|c|}
\hline Variable & Description & $\begin{array}{c}\text { In } \\
\text { questionnaire }\end{array}$ \\
\hline $\begin{array}{l}\text { Adoption } \\
\text { status }\end{array}$ & $\begin{array}{l}1 \text { if the respondent has used an Internet-based platform to receive } \\
\text { orders, } 0 \text { otherwise; }\end{array}$ & Question 6 \\
\hline $\begin{array}{l}\text { Status quo } \\
\text { bias }\end{array}$ & 1 if the respondent comes from Anhui Province, 0 otherwise; & Question 7 \\
\hline Risk tolerance & $\begin{array}{l}3 \text { if the respondent chooses } \mathrm{A}, 2 \text { if the respondent chooses } \mathrm{B}, 1 \text { if } \\
\text { the respondent chooses } \mathrm{C} \text {; }\end{array}$ & $\begin{array}{l}\text { Question } \\
8 / \text { Scenario test }\end{array}$ \\
\hline $\begin{array}{l}\text { Service } \\
\text { orientation }\end{array}$ & $\begin{array}{l}1 \text { if the respondent chooses } \mathrm{A}, 2 \text { if the respondent chooses } \mathrm{B}, 3 \text { if } \\
\text { the respondent chooses } \mathrm{C}, 4 \text { if the respondent chooses D, and } 5 \text { if } \\
\text { the respondent chooses E; }\end{array}$ & $\begin{array}{l}\text { Question } \\
\text { 9/Scenario test }\end{array}$ \\
\hline Gender & 1 if the respondent is female, 0 if the respondent is male; & Question 1 \\
\hline Age & 0 if the respondent is under $28 ; 1$ if the respondent is older than 28 ; & Question 2 \\
\hline $\begin{array}{l}\text { Educational } \\
\text { background }\end{array}$ & $\begin{array}{l}0 \text { if the respondent's educational background is junior high school } \\
\text { or lower; } 1 \text { if the respondent's educational background is senior } \\
\text { high school or higher; }\end{array}$ & Question 3 \\
\hline $\begin{array}{l}\text { Driving } \\
\text { experience }\end{array}$ & $\begin{array}{l}0 \text { if the respondent's driving experience is less than } 12 \text { years; } 1 \text { if } \\
\text { the respondent's driving experience is more than } 12 \text { years; }\end{array}$ & Question 4 \\
\hline Firm size & $\begin{array}{l}1 \text { if the firm size is less than } 10 \text { trucks; } 2 \text { if the firm size is between } \\
11 \text { and } 20 \text { trucks; } 3 \text { if the firm size is between } 21 \text { and } 30 \text { trucks; } 4 \\
\text { if the firm size is more than } 31 \text { trucks. }\end{array}$ & Question 5 \\
\hline
\end{tabular}


475 and 1, while the independent variable, moderate variables and control variables are

476 either dummy variable or count variables, the logistic regression fit our research well,

477 enabling us to predict the values of a dichotomous dependent variable (Y) which takes

478 only two values, 0 or 1 , depending on a set of explanatory variables that can be either

479 quantitative or categorical variables (Wooldridge, 2008).

$480 \quad$ 6.2 Data Analysis and Results

481 The descriptive statistics for all variables and the correlations of the variables are

482 reported in Table 3 and Table 4 respectively. We notice that most of the correlation

483 values are below 0.5. Furthermore, we also conduct the Variance Inflation Factor (VIF)

484 test. The mean VIF was 1.1, below the rule-of-thumb cutoff of 10 (Ryan, 1997).

485 Therefore, we believe that multicollinearity does not significantly affect our results.

486

487

Table 3. Descriptive Statistics of Variables

\begin{tabular}{llll}
\hline & $\mathrm{N}$ & Mean & SD \\
\hline Adoption status & 178 & 0.53 & 0.5 \\
Status quo bias & 178 & 0.46 & 0.5 \\
Risk tolerance & 178 & 2.04 & 0.609 \\
Service orientation & 178 & 3.72 & 1.377 \\
Gender & 178 & 0.04 & 0.208 \\
Age & 178 & 0.75 & 0.433 \\
Educational background & 178 & 0.93 & 0.261 \\
Driving experience & 178 & 0.54 & 0.499 \\
Firm size & 178 & 2.69 & 1.133 \\
\hline
\end{tabular}

488

Table 4. Correlations of Variables

\begin{tabular}{|c|c|c|c|c|c|c|c|c|c|c|}
\hline & VIF & (1) & (2) & (3) & (4) & (5) & (6) & (7) & (8) & (9) \\
\hline (1) Adoption status & & 1 & & & & & & & & \\
\hline (2) Status quo bias & 1.18 & $-0.831^{* * *}$ & 1 & & & & & & & \\
\hline (3) Risk tolerance & 1.07 & $-0.190^{* *}$ & $0.191^{* * *}$ & 1 & & & & & & \\
\hline (4) Service orientation & 1.09 & 0.075 & $-0.143^{*}$ & $-0.167^{* *}$ & 1 & & & & & \\
\hline (5) Gender & 1.10 & 0.094 & -0.092 & -0.061 & 0.103 & 1 & & & & \\
\hline (6) Age & 1.24 & $-0.327^{* * *}$ & $0.321^{* * *}$ & $0.150^{* *}$ & $-0.248^{* * *}$ & $-0.127^{*}$ & 1 & & & \\
\hline (7) Education & 1.03 & $0.170^{* *}$ & -0.087 & -0.021 & 0.038 & -0.043 & -0.111 & 1 & & \\
\hline (8) Driving experience & 1.10 & $0.254^{* * *}$ & $-0.219^{* * *}$ & -0.062 & $0.137^{*}$ & -0.074 & $-0.262^{* * *}$ & $0.134^{*}$ & 1 & \\
\hline (9) Firm size & 1.06 & -0.021 & 0.038 & 0.037 & -0.045 & $-0.227^{* * *}$ & 0.059 & 0.036 & -0.035 & 1 \\
\hline
\end{tabular}

Note, ${ }^{* * *} \mathrm{p}<0.01,{ }^{* *} \mathrm{p}<0.05,{ }^{*} \mathrm{p}<0.1$. 
The results of the logistic regression are presented in Table 5. Model 1 is the 492 basic model, containing only control variables; Model 2 is the primary model to test 493 hypothesis 1, containing independent variable and control variables; Model 3 is to test 494 hypothesis 2, containing independent variable, moderator 1 (risk tolerance) and 495 control variables; Model 4 is to test hypothesis 3, containing independent variable, 496 moderator 2 (service orientation) and control variables. Model level VIF tests are conducted to make sure the multicollinearity does not significantly affect our results.

Model 1 contains control variables only, including gender, age, educational background, driving experience, and firm size. Except for firm size, all others are significant at 10\% significance level. The gender, educational background and driving experience are positive, while age is negative. We found that gender has the largest impact on innovation adoption, followed by educational background. Older people are more likely to be resistant to innovation. This is consistent with reality.

In Model 2, the status quo bias is added. As shown, the status quo bias is negative $(\beta=-4.780)$ and significant at $1 \%$ significance level, indicating that status quo bias negatively affects adoption status. Thus, hypothesis $1(\boldsymbol{H 1})$ is supported. Table 5. Logistic Regression Results

\begin{tabular}{|c|c|c|c|c|}
\hline Variable & Model 1 & Model 2 & Model 3 & Model 4 \\
\hline Gender & $\begin{array}{l}1.209 \\
(0.972)\end{array}$ & $\begin{array}{l}0.928 \\
(1.699)\end{array}$ & $\begin{array}{l}0.894 \\
(2.118)\end{array}$ & $\begin{array}{l}.311 \\
(1.985)\end{array}$ \\
\hline Age & $\begin{array}{l}-1.458^{* * *} \\
(0.442)\end{array}$ & $\begin{array}{l}-0.791 \\
(0.793)\end{array}$ & $\begin{array}{l}-0.510 \\
(0.863)\end{array}$ & $\begin{array}{l}-1.405 \\
(1.009)\end{array}$ \\
\hline Educational background & $\begin{array}{l}1.175 \\
(0.720)\end{array}$ & $\begin{array}{l}1.983^{* *} \\
(0.983)\end{array}$ & $\begin{array}{l}2.629^{* *} \\
(1.144)\end{array}$ & $\begin{array}{l}1.868^{*} \\
(0.998)\end{array}$ \\
\hline Driving experience & $\begin{array}{l}0.807^{* *} \\
(0.337)\end{array}$ & $\begin{array}{l}0.801 \\
(0.576)\end{array}$ & $\begin{array}{l}1.043^{*} \\
(0.609)\end{array}$ & $\begin{array}{l}0.692 \\
(0.613)\end{array}$ \\
\hline Firm size & $\begin{array}{l}0.040 \\
(0.149)\end{array}$ & $\begin{array}{l}0.133 \\
(0.252)\end{array}$ & $\begin{array}{l}0.135 \\
(0.263)\end{array}$ & $\begin{array}{l}0.139 \\
(0.258)\end{array}$ \\
\hline Status quo bias & & $\begin{array}{l}-4.780^{* * *} \\
(0.590)\end{array}$ & $\begin{array}{l}-10.613^{* * *} \\
(2.586)\end{array}$ & $\begin{array}{l}-2.512^{*} \\
(1.489)\end{array}$ \\
\hline Risk tolerance & & & $\begin{array}{l}-1.720^{* *} \\
(0.734)\end{array}$ & \\
\hline Service orientation & & & & $\begin{array}{l}-0.004 \\
(0.293)\end{array}$ \\
\hline Status quo bias $\times$ Risk tolerance & & & $\begin{array}{l}2.598^{* *} \\
(1.042)\end{array}$ & \\
\hline Status quo bias $\times$ Service orientation & & & & $\begin{array}{l}-0.751^{*} \\
(0.434)\end{array}$ \\
\hline $\mathrm{N}$ & 178 & 178 & 178 & 178 \\
\hline Pseudo R-squared & $12.49 \%$ & $61.91 \%$ & $65.03 \%$ & $64.53 \%$ \\
\hline VIF & 1.08 & 1.11 & 4.56 & 3.16 \\
\hline
\end{tabular}

Note, Robust standard errors in parentheses; ${ }^{* * *} \mathrm{p}<0.01,{ }^{* *} \mathrm{p}<0.05,{ }^{*} \mathrm{p}<0.1$. 
In Models 3 and 4, we examine the moderating effects of risk tolerance and service 510 orientation respectively. In model 3, it is indicated that the interaction effect of status quo bias 511 and risk tolerance on adoption status is statistically positive $(\beta=2.598)$ at $5 \%$ significance 512 level, which supports our hypothesis 2 (H2). In model 4, we found that the interaction effect 513 of status quo bias and service orientation on adoption status is statistically negative $(\beta=$ $514-0.751)$ at $10 \%$ significance level, which confirms our hypothesis 3 . It is worth noting that the value of pseudo R-squared from Model 1 to Model 4 increases from 12.49\% to $64.53 \%$, indicating a better model fit with the social-psychological factors.

517 Following De Veaux, Velleman and Bock, (2015), we conducted robustness 518 check based on log odds ratios to justify the interaction effects. As shown in Equation

519 (1), the $\log$ odds ratios can be estimated in the form of $\operatorname{Ln}\left(\frac{\widehat{p}}{1-\hat{p}}\right)$, where $\hat{p}$ is the 520 estimation of $\mathrm{P}$ defined in equation (1). The interaction effect between status quo bias 521 and risk tolerance, Status quo bias and Service orientation are shown in Figure 6 and 522 Figure 7, respectively. As shows in Figure 6, when risk tolerance values 1 (RT=1), the 523 slope is -8.015 , smaller than that of $\mathrm{RT}=3$, which is -2.819 . This means the possibility 524 of innovation adoption of $\mathrm{RT}=1$ reduces faster than that of $\mathrm{RT}=3$ as predicted in $\mathrm{H} 2$.

525 Similarly, Figure 7 shows that when service orientation values $1(\mathrm{SO}=1)$, the slope is $526-3.263$, larger than that of $\mathrm{SO}=5$, which is -6.267 . This means the possibility of 527 innovation adoption of $\mathrm{SO}=1$ reduces slower than that of $\mathrm{SO}=5$ as predicted in $\mathrm{H} 3$.

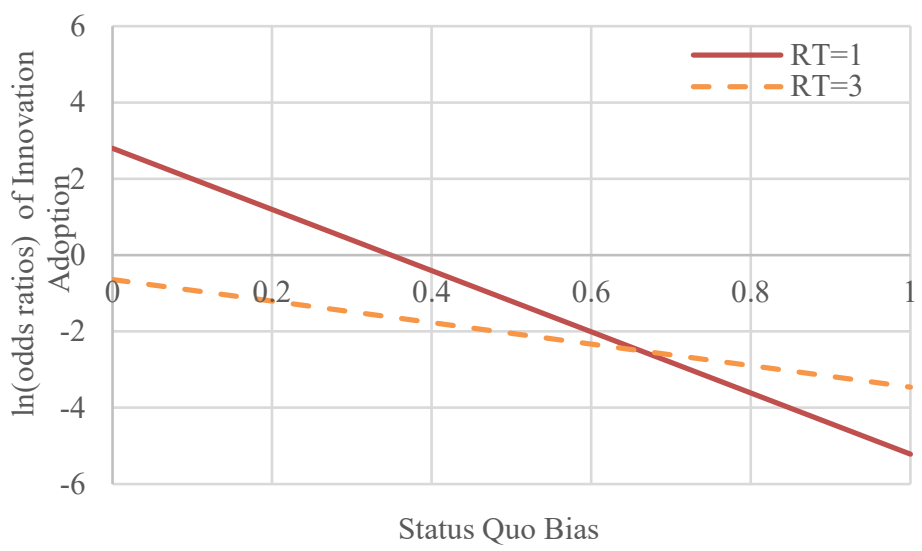

530 Figure 6 Interaction Effect Between Status quo bias and Risk tolerance on Adoption 


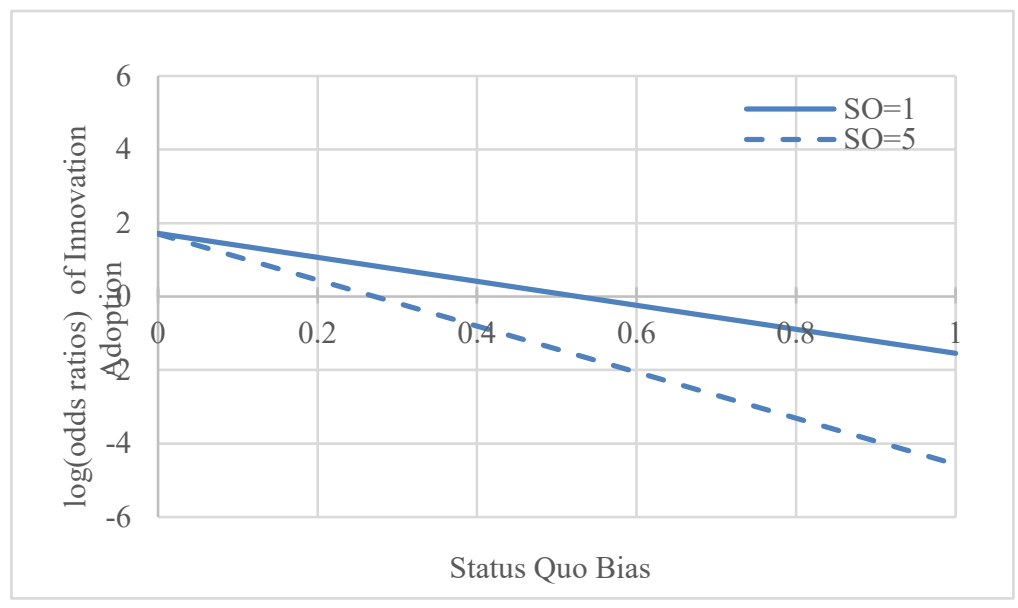

Figure 7. Interaction Effect Between Status quo bias and Service orientation on Adoption

\section{Conclusions and Implications}

535 Our research highlights the social-psychological factors underlying innovation adoption during the early stage in the transportation industry. In particular, rooted in innovation diffusion theory and innovation resistance theory, we develop a two-stage innovation decision model to explore its impact and test it empirically. We emphasize the fact that innovation diffusion may fail during the early stage simply because the potential adopters are not cognitively ready to accept new technologies and patterns,

541 especially in the case of individuals who are more satisfied with their status quo.

542 Furthermore, once overcoming the status quo bias, individuals proceed to the next

543 stage of decision-making, where they have to evaluate innovation according to their

544 own criteria. We propose that the evaluation stage also unfolds on a social-economic 545 basis. A person's personality traits, such as sensation seeking, openness to experience, dogmatism, and locus of control, play an important role in the individual's inclination to adopt innovation. Using a case study regarding internet-based platformization in

548 the Chinese container trucking industry, we empirically confirm our proposed 549 hypotheses, namely, that risk tolerance positively moderates the influence of status 550 quo bias on the innovation adoption decision, whereas the effect on it of 551 service-orientation is negative.

552 The findings of this paper can help trucking company managers to understand 553 the fact that technology excellence and cost advantage do not necessarily lead to 554 success in introducing new products and patterns. Innovation adoption, usually associated with change in behavior, may conflict with existing social norms, values, 
556 and individual usage patterns, especially during the early stage when the economic 557 benefits cannot be fully recognized due to limited information disclosure. Without 558 sufficient incentives, individuals tend to strive for consistency and want to maintain 559 the status quo, postponing their decision until the time is ripe. Therefore, attracting 560 high risk tolerant and less service-oriented individuals to adopt a new business model 561 (innovation) can be considered a practical approach to accumulating enough users to 562 trigger the bandwagon effect. This roadmap is even more feasible if taking a proper 563 training program, incentive plan and regulation into account, which can be regarded 564 as a socialization process that follows an individual's innovation adoption.

565 As one of the preliminary studies focusing on the impact of social-psychological 566 processes on innovation adoption in the transportation industry, the two-stage research 567 framework we proposed in our research lays a good foundation and constructive 568 reference for further researches in this field. In particular, our research framework 569 provides a template for employing the same combination of qualitative method and 570 quantitative method, leveraging their respective strengths to investigate the specifics 571 of operator behavior. We believe that this approach is especially suitable for generating and testing theory in transportation studies that are rooted in the contextualized phenomenon. In the future, we think two promising directions in our

574 framework are worthy of attention, including: 1) further refinement of the research model by introducing different variables in both stages. In particular, our results

576 demonstrate that age has significant negative effect on the adoption of truck-cargo 577 matching system while driving experience has significantly positive impact. This 578 indicates that older driver tends to has less willingness to adopt the cargo-truck 579 matching system. The driver with more experience is more likely to adopt the new 580 technology. We also found that the gender and firm size is irrelevant to the new 581 technology adoption in all models. Although these variables are not directly related to our research question, it still worth to investigate into the mechanism underlies this phenomenon for future research; and 2) focusing on more stages than just the early stage, by investigating the underlying mechanisms leading to innovation adoption decisions being made. 


\section{Reference}

590 Abrahamson, E., and Rosenkopf, L. (1993). Institutional and competitive bandwagons:

591 using mathematical modeling as a tool to explore innovation diffusion. Academy of 592 Management Review, 18(3), 487-517.

593 Bagozzi, R. P., and K.H. Lee. (1999). Consumer resistance to, and acceptance of, 594 innovations. Advances in Consumer Research, 26 (1), 218-25.

595 Cantor, D. E., Corsi, T. M., \& Grimm, C. M. (2006). Safety technology adoption 596 patterns in the US motor carrier industry. Transportation Journal, 20-45.

597 Cantor. D. E, Corsi. T.M, \& Grimm. C.M. (2008) Determinants of motor carrier safety 598 technology adoption. Transportation Research Part E Logistics \& Transportation 599 Review, 44(5), 932-947.

600 Chen. S. K., Wang. H, and Meng, Q. (2019), Designing autonomous vehicle incentive 601 program with uncertain vehicle purchase price, Transportation Research Part C: 602 Emerging Technologies, 103, 226-245.

603 Chen, Y., Zhang, Q., Chen, S., and Wan, Z. (2019). Chinese third-party shipping 604 internet platforms: thriving and surviving in a two-sided market (2013-2016). 605 Transport Policy. In Press.

606 Creswell, J., W. (2009). Editorial: mapping the field of mixed methods 607 research. Journal of Mixed Methods Research, 3(2), 95-108.

608 De Veaux, R, P. F. Velleman \& D. E. Bock, 2015, Stats: Data and Models, Pearson; 609 4th edition

610 Dhebar, A. (1996). Speeding high-tech producer, meeting the balking customer. Sloan 611 Management Review, 37(2), 37-49.

612 Golob, T. F., \& Regan, A. C. (2002). Trucking industry adoption of information 613 technology: a multivariate discrete choice model. Transportation Research Part C: 614 Emerging Technologies, 10(3), 205-228.

615 Gourville, J. T. (2006). Eager sellers and stony buyers. Understanding the psychology 616 of new-product adoption. Harvard Business Review, 84 (6), 98-106.

617 Gunasekaran, A., and Ngai, E. W. T. (2008). Adoption of e-procurement in Hong 618 Kong: an empirical research. International Journal of Production Economics, 113(1), $619 \quad 159-175$.

620 Hoeffler, S. (2003). Measuring preferences for really new products. Journal of 621 Marketing. Research, 40 (4), 406-20. 
622 Joachim, V., Spieth, P., and Heidenreich, S. (2018). Active innovation resistance: an

623 empirical study on functional and psychological barriers to innovation adoption in 624 different contexts. Industrial Marketing Management, 17(5),95-107.

625 Johnson, E.J., Hershey, J., Meszaros, J., Kunreuther, H., 1993. Framing, probability 626 distortions, and insurance decisions. Journal of Risk and Uncertainty, 7, 35-51.

627 Johnson, R. B., and Onwuegbuzie, A. J. (2004). Mixed Methods Research: A 628 Research Paradigm Whose Time Has Come. Educational Researcher, 33(7), 14-26.

629 Kahneman, D., Thaler, R., 2006. Anomalies: utility maximisation and experienced 630 utility. Journal of Economic Perspectives 20, 221-234.

631 Kahneman, D., \& Tversky, A. (1979). Prospect theory: an analysis of decision under 632 risk. Econometrica, 47(2), 263-291.

633 Kleijnen, M., N. Lee, and M. Wetzels. (2009). An exploration of consumer resistance 634 to innovation and its antecedents. Journal of Economic Psychology, 30 (3),344-57.

635 Latinopoulos, C. , Sivakumar, A. , \& Polak, J. W. . (2017). Response of electric 636 vehicle drivers to dynamic pricing of parking and charging services: risky choice in 637 early reservations. Transportation Research Part C Emerging Technologies, 80, 638 175-189.

639 Laukkanen, P., S. Sinkkonen, and T. Laukkanen. (2008). Consumer resistance to 640 internet banking: Postponers, opponents and rejectors. International Journal of Bank 641 Marketing, 26 (1), 440-55.

642 Liu. P, Guo Q.R, Ren. F, Wang. L, Xu. Z.G. (2019). Willingness to pay for 643 self-driving vehicles: Influences of demographic and psychological factors, 644 Transportation Research Part C: Emerging Technologies, 100, 306-317.

645 Matopoulos, A., Vlachopoulou, M., Manthou, V. (2007). Exploring the impact of 646 e-business adoption on logistics processes: empirical evidence from the food industry. 647 International Journal of Logistics Research and Applications, 10 (2), 109-122.

648 Maguire, S., and Lawrence, H. T. B. (2004). Institutional entrepreneurship in 649 emerging fields: HIV/AIDS treatment advocacy in Canada. The Academy of 650 Management Journal, 47(5), 657-679.

651 Metcalfe, R. , \& Dolan, P. . (2012). Behavioural economics and its implications for 652 transport. Journal of Transport Geography, 24(24), 503-511.

653 Meyer, J. W., and Rowan, B. (1977). Institutionalized organizations: formal structure 654 as myth and ceremony. American Journal of Sociology, 83(2), 340-363. 
655 Morganti, E., and Browne, M. (2018). Technical and operational obstacles to the 656 adoption of electric vans in France and the UK: an operator perspective. Transport 657 Policy, 63, 90-97.

658 Nabih, M. I., J. G. Bloem, and T. B. C. Poiesz. (1997). Conceptual issues in the study 659 of innovation adoption behavior. Advances in Consumer Research, 24,190-96.

660 Nguyen, H. O. (2013). Critical factors in e-business adoption: evidence from 661 Australian transport and logistics companies. International Journal of Production 662 Economics,146(1), 300-312.

663 Noussair, C., Robin, S., and Ruffieux, B. (2004). Do consumers really refuse to buy 664 genetically modified food?. Economic Journal, 114(492), 102-120.

665 Park, C.W., Jun, S.Y., MacInnis, D.J., 2000. Choosing what I want versus rejecting 666 what I do not want: an application of decision framing to product option choice 667 decisions. Journal of Marketing Research, 37, 187-202.

668 Petschnig, M., Heidenreich. S., and Heidenreich, S. (2014). Innovative alternatives 669 take action-investigating determinants of alternative fuel vehicle adoption. 670 Transportation Research Part A: Policy and Practice, 61, 68-83.

671 Oláh, Judit, Karmazin, G., Pet, Károly, and Popp, József. (2017). Information 672 technology developments of logistics service providers in Hungary. International 673 Journal of Logistics Research and Applications, 21(3), 332-344.

674 Oliveira, T., and Martins, M.F. (2010). Understanding e-business adoption across 675 indus- tries in European countries. Industrial Management and Data Systems, 110 (9), $676 \quad 1337-1354$.

677 Orlikowski, W. J., and Barley, S. R. (2001). Technology and institutions: what can 678 research on information technology and research on organizations learn from each 679 other? MIS Quarterly, 25(2), 145-165.

680 Quek, K.B., and Wang, Y. (2017). Does obligational contracting lead to better 681 performance? A comparison of global carmakers' supply chain management 682 approaches in Australia. International Journal of Logistics Research and Applications, $68320(5), 444-458$.

684 Ram, S., and Sheth, J. N. (1989). Consumer resistance to innovations: The marketing 685 problem and its solutions. Journal of Consumer Marketing, 6(2), 5-14.

686 Rogers, E.M. (1976). New product adoption and diffusion. Journal of Consumer 687 Research, 2 (4), 290-301.

688 Rogers, E.M. (2003). Diffusion of Innovations, 5th Edition, Free Press, New York. 
Ryan, T.P. (1997). Modern Regression Methods. Wiley-InterScience.

690 Sheth, J. N. (1981). Innovation resistance. The less developed concept (LDC) in 691 diffusion research. Research, 4, 273-82.

692 Selznick, P. (1957). Leadership in Administration: A Sociological Interpretation. 693 Evanston, IL: Row, Peterson.

694 Subramanian, N., Abdulrahman, M. D., and Zhou, X. (2015). Reprint of "integration 695 of logistics and cloud computing service providers: cost and green benefits in the 696 Chinese context”. Transportation Research Part E: Logistics and Transportation 697 Review, 74, 81-93.

698 Szmigin, I., and Foxall, G. (1998). Three forms of innovation resistance: the case of 699 retail payment methods. Technovation, 18(6/7), 459-468.

700 Talke, K., and Heidenreich, S. (2013). How to overcome pro-change bias: 701 Incorporating passive and active innovation resistance in innovation decision models. 702 Journal of Product Innovation Management, 31(5), 894-907.

703 Trope, Y., Liberman, N., \& Wakslak, C. (2007). Construal levels and psychological 704 distance. effects on representation, prediction, evaluation, and behavior. Journal of 705 Consumer Psychology, 17(2), 83-95;

706 Wang, S.Y., Wang, J., Li, J., Wang, J. P., and Liang, L. (2018), Policy implications for 707 promoting the adoption of electric vehicles: Do consumer's knowledge, perceived risk 708 and financial incentive policy matter?, Transportation Research Part A: Policy and 709 Practice, 117,58-69.

710 Wolf, A. and Seebauer, S. (2014). Technology adoption of electric bicycles: a survey 711 among early adopters, Transportation Research Part A: Policy and Practice, 69, 712 196-211.

713 Woodside, A. G., and Biemans, W. G. (2005). Modeling innovation, manufacturing, 714 diffusion and adoption/rejection processes. Journal of Business and Industrial 715 Marketing, 20(7), 380-393.

716 Wooldridge, J. M. (2008). Introductory Econometrics. South Western College.

717 Zeng, X. H, Li, H. C., Song, D. F., Yang, N. N., and Wang, Z. W. (2018). EVT

718 Logistics Vehicle Cost Recovery Cycle and Economic Analysis, IFAC-PapersOnLine, 719 51(31), 415-422. 
724 Part A: Basic Situation

B. Female.

3. Educational background:

730

A. Primary school or below;

B. Junior high school;

733

C. Senior high school;

734

735

D. Above senior high school.

736

4. Your truck driving experience:

737

A. Less than 6 years;

738

B. 7-12 years;

739

C. 13-18 years;

740

D. 19-24 years;

E. 25 years or above.

5. How many trucks do you have in your company?

A. 10 trucks or less;

744

745

B. 11 to 20 trucks;

746

C. 21 to 30 trucks;

D. 31 trucks or more

749

750

6. Have you ever received orders though an internet-based platform?

751

752

A. Yes;

B. No.

753

7. Your hometown: (Province)

\section{Part B. Scenario Choice:}

8. Scenario I: When you are on your way to $\mathrm{C}$ to deliver a consignment, another customer requests that you collect a shipment from D. If you accept this shipment, you have to make a detour to receive the goods from $\mathrm{D}$, which may result in the chance of a one hour delay in the delivery to C. Will you accept the additional

760 a. I won't, because there is a chance of a one hour delay in my delivery to C;

761 b. If the chance of a one hour delay in the delivery to $\mathrm{C}$ is less than $15 \%$, I will;

762 c. If the chance of a one-hour delay in the delivery to $\mathrm{C}$ is less than $30 \%$, I will. 
763 9. Scenario II: You are assigned to collect cargo at place A at 10 o' clock tomorrow 764 morning (Monday). If you are living in place B, which is located 65 kilometers 765 from A, when do you plan to set off to drive to A to receive the cargo? (Note: 766 Regardless of traffic congestion, it usually takes about an hour to drive from B to $767 \quad$ A.)

768 a. Later than 09:00

769 b. $08: 30$ to $09: 00$

770 c. $08: 00$ to $08: 30$

771 d. $07: 30$ to $08: 00$

772 e. Earlier than 07:30 